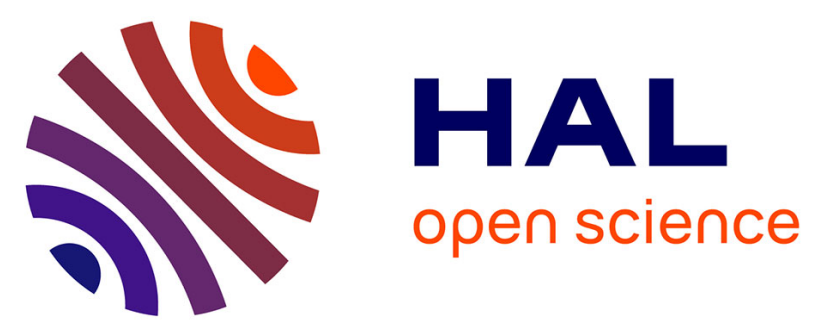

\title{
Prospective comparison of $(1,3)$-beta-D-glucan detection using colorimetric and turbidimetric assays for diagnosing invasive fungal disease
}

Alexandre Alanio, Maud Gits-Muselli, Nicolas Guigue, Blandine Denis, Anne Bergeron, Sophie Touratier, Samia Hamane, Stéphane Bretagne

\section{To cite this version:}

Alexandre Alanio, Maud Gits-Muselli, Nicolas Guigue, Blandine Denis, Anne Bergeron, et al.. Prospective comparison of (1,3)-beta-D-glucan detection using colorimetric and turbidimetric assays for diagnosing invasive fungal disease. Medical Mycology, 2021, pp.myab016. 10.1093/mmy/myab016 . pasteur-03226316

\section{HAL Id: pasteur-03226316}

https://hal-pasteur.archives-ouvertes.fr/pasteur-03226316

Submitted on 14 May 2021

HAL is a multi-disciplinary open access archive for the deposit and dissemination of scientific research documents, whether they are published or not. The documents may come from teaching and research institutions in France or abroad, or from public or private research centers.
L'archive ouverte pluridisciplinaire HAL, est destinée au dépôt et à la diffusion de documents scientifiques de niveau recherche, publiés ou non, émanant des établissements d'enseignement et de recherche français ou étrangers, des laboratoires publics ou privés.

\section{(ㄷ)(1) $\$$}

Distributed under a Creative Commons Attribution - NonCommerciall 4.0 International 
1 Prospective comparison of (1,3)-beta-D-glucan detection using colorimetric and turbidimetric assays for diagnosing invasive fungal disease

Alexandre Alanio ${ }^{1,2,3, *}$, Maud Gits-Muselli ${ }^{1,2}$, Nicolas Guigue ${ }^{1}$, Blandine Denis ${ }^{4}$, Anne Bergeron ${ }^{5}$, Sophie Touratier ${ }^{6}$, Samia Hamane ${ }^{1}$, and Stéphane Bretagne ${ }^{1,2,3}$

1 Laboratoire de Parasitologie-Mycologie, Groupe Hospitalier Lariboisière, Saint-Louis,

9 Fernand Widal, Assistance Publique-Hôpitaux de Paris (AP-HP), Paris, France

102 Université de Paris, Paris, France

$11{ }^{3}$ Institut Pasteur, Unité de Mycologie Moléculaire, CNRS UMR2000, Paris, France

$12{ }^{4}$ Groupe Hospitalier Lariboisière, Saint-Louis, Fernand Widal, Assistance Publique-Hôpitaux 13 de Paris (AP-HP), Paris, France

$14{ }^{5}$ Groupe Hospitalier Lariboisière, Saint-Louis, Fernand Widal, Assistance Publique-Hôpitaux 15 de Paris (AP-HP), Paris, France

$16{ }^{6}$ Groupe Hospitalier Lariboisière, Saint-Louis, Fernand Widal, Assistance Publique-Hôpitaux 17 de Paris (AP-HP), Paris, France

Short Title: Prospective comparison of colorimetric and turbidimetric $1 \rightarrow 3)-\beta$-D-glucan assays Keywords: $(1 \rightarrow 3)-\beta$-D-glucan, colorimetric assay, turbidimetric assay, invasive fungal disease 21

* Corresponding author: Alexandre Alanio, MD, PhD, Molecular Mycology unit, Institut Pasteur, 2325 rue du Dr Roux 75724 Paris Cedex 15; email: alexandre.alanio@pasteur.fr; Tel: $24+33140613255$; Fax: +33145688420 


\section{Abstract}

Serum $(1 \rightarrow 3)-\beta-D-g l u c a n(B D G)$, an antigen that is common to several fungi, is detected in some invasive fungal diseases (IFDs). Colorimetric or turbidimetric detection is the basis of two different commercial kits, the Fungitell assay (FA) and the Wako assay (WA), and we compared the WA to the FA.

We used both assays over a 4-month period to prospectively test 171 patients (sex ratio $M / F$, $60 \%$; mean age, $48 \pm 16$ years) who mainly had haematological conditions (62\%) and who experienced episodes $(n=175)$ of suspected IFI. The tests were performed according to the manufacturers' recommendations.

Twenty-three episodes due to BDG-producing fungi were diagnosed (pneumocystosis, $n=12$; invasive aspergillosis, $n=5$; candidemia, $n=3$; invasive fusariosis, $n=2$; hepato-splenic candidiasis, $n=1$ ). Both assays provided similar areas under the receiver operating characteristic curves ( $A \cup C=0.9)$. Using the optimised positivity thresholds $(\geq 120 \mathrm{pg} / \mathrm{ml}$ for $F A$ and $\geq 4 \mathrm{pg} / \mathrm{ml}$ for WA), the sensitivity and specificity were $81.8 \%$ (95\% confidence interval $\mathrm{Cl}$ : 61.5-92.7) and $94.8 \%(95 \% \mathrm{Cl}: 90.1-97.3)$ for $\mathrm{FA}$ and $81.8 \%(95 \% \mathrm{Cl}: 61.5-92.7), 95.4 \%$ (95\%Cl: 90.9-97.8) for WA. Negative predictive value was $97.3 \%$ (95\%Cl: 93.3-99.0) for both tests. If the manufacturer's positivity threshold $(\geq 11 \mathrm{pg} / \mathrm{ml})$ was applied, the WA sensitivity decreased to $50 \%$. Among 71 patients with bacterial infections, $21.1 \%$ were FA-positive $(\geq 80$ $\mathrm{pg} / \mathrm{ml})$ and $5.6 \%$ were WA-positive $\left(\geq 11 \mathrm{pg} / \mathrm{ml} ; \mathrm{p}<10^{-2}\right)$.

The WA performed similarly compared to the FA when an optimised cut-off was used to diagnose IFD. The WA is a single sample test that is clinically relevant when a prompt therapeutic decision is required.

\section{Lay summary}

50 Serum $(1 \rightarrow 3)$ - $\beta$-D-glucan testing is dominated by two kits including Fungitell colorimetric assay

51 (FA) and the Wako turbidimetric assay (WA). We compared them prospectively and observed

52 that they perform similarly when selecting their optimal threshold ( $\geq 120 \mathrm{pg} / \mathrm{ml}$ for $F A$ and $\geq 4$

$53 \mathrm{pg} / \mathrm{ml}$ for WA). 


\section{INTRODUCTION}

The prognosis of invasive fungal diseases (IFD) is still worrisome and one of the reasons for this is the poor performance of microbiological tools, and more particularly for an early diagnosis. ${ }^{1,2}$ Because the clinical and imaging signs of IFDs are not specific, therapy is either delayed or prescribed on a prophylaxis or empirical schedule, which risks potential side effects, the possibility of resistance selection, and/or increased costs. ${ }^{3}$ Thus, biomarkers of IFD are required to improve the use of antifungal drugs. ${ }^{4,5}$

Among the biomarkers, the fungal antigens galactomannan (GM) and $(1 \rightarrow 3)-\beta-D$ glucan (BDG) have shown sufficient efficacy to be included in the diagnostic criteria of IFD. ${ }^{6}$ While GM is more specific to Aspergillus spp. infection detection, BDG is produced by a wide variety of medically important fungi, with the exception of Mucorales and Cryptococcus spp. ${ }^{7}$ Indeed, Cryptococcus spp. do produce BDG which can be detected in cerebrospinal fluid in cryptococcal meningitis but in a too little quantity to be detected in serum. ${ }^{8}$ BDG assay performance is especially good for the diagnosis of Pneumocystis pneumonia (PCP), with a pooled sensitivity and specificity of $95 \%-96 \%$ and $84 \%-86 \%$, respectively. ${ }^{9}$ Thus, specific recommendations for PCP diagnosis have been proposed in patients with haematological malignancies using the BDG results. ${ }^{10}$ The assay performance for the other IFDs, not including PCP, is lower and has greater heterogeneity, which is between $67 \%-84 \%$ and $79 \%-90$ for the pooled sensitivity and specificity, respectively. ${ }^{7}$

In addition to the differences between the IFDs and the populations that are at risk for IFDs, an additional variability factor is that there are several different commercial assays for $\mathrm{BDG}$, in contrast to $\mathrm{GM}$ detection which has been widely performed using a unique assay. ${ }^{11}$ For BDG detection, at least five assays have been released for diagnostic use, as follows: Fungitell (Associates of Cape Cod, Inc., East Falmouth, MA, USA), B-Glucan Test Wako (FUJIFILM Wako Chemicals, Osaka, Japan), Fungitec G-Test MK (Seikagaku Corporation, Kogyo, Tokyo, Japan), B-G Star (Maruha Corporation, Osaka, Japan or Maruha-Nichiro, Foods Inc., Tokyo, Japan), and Dynamiker Fungus (Dynamiker Biotechnology Co., Ltd, Tianjin, China). ${ }^{12}$ Fungitell assay (FA) was approved in the United States in $2004,{ }^{13}$ whereas the Wako assay (WA) only recently received European marketing approval. The difference between FA and WA is that they rely on the horseshoe crab as the source of the amoebocyte lysate, which is from Limulus polyphemus (FA) or Tachypleus tridentatus (WA), and the mode of revelation, colorimetric (FA) or turbidimetric (WA), is also different between the tests. This results in different reactivity for BDG detection and cut-offs that define a positive test result, as follows: $\geq 80 \mathrm{pg} / \mathrm{ml}$ for FA and $\geq 11 \mathrm{pg} / \mathrm{ml}$ for WA, according to the manufacturers.

The recent availability of WA has stimulated comparative studies with FA, first in $2011^{14}$ and in more recent years. ${ }^{15-18}$ These comparative studies were performed on archived serum 
samples that were selected to diagnose PCP, ${ }^{15}$ candidaemia, ${ }^{16}$ or several IFDs, ${ }^{14,17,18}$ and selected controls have also been used. In contrast to these retrospective studies, we performed a prospective comparison of the analytical capacities of the two assays to evaluate the feasibility of their routine use.

\section{MATERIALS AND METHODS}

\section{Patients and definitions}

All the BDG requests by the clinicians from December 21, 2018 to April 23, 2019 were included without selection on the basis of the underlying disease. The classification as proven, probable, or no-IFD was based on criteria from the European Organisation for Research and Treatment of Cancer and from the Invasive Fungal Infections Cooperative Group and the Mycoses Study

103 Group Education and Research Consortium (EORTC/MSGERC). ${ }^{6}$ For invasive mould infections, the medical files were analysed to classify the patients according to our local committee, as was previously reported..$^{19} \mathrm{FA}$ results were transmitted to the clinicians as part of the routine work-up for an IFD diagnosis. WA tests were performed by two of the authors who were blinded to the routine FA results. Because the results were part of an evaluation, WA results were not transmitted to the clinicians to avoid any interference with the clinical decision. Because some patients were hospitalised several times and tested each time for suspicion of IFD, we defined different episodes of BDG as being tested at least 30 days apart

111 during two different hospitalisations. The fist positive serum per episode was selected for 112 analysis.

\section{Test realisation}

115 Both assays were performed according to the manufacturers' recommendations on the same day. For the FA, $5 \mu \mathrm{l}$ of serum was added to $20 \mu \mathrm{l}$ of pre-treatment reagent in a glucan-free 96-well plate. After $10 \mathrm{~min}$ at $37^{\circ} \mathrm{C}, 100 \mu \mathrm{l}$ of Fungitell reagent was added to the pre-treated sample and the kinetic colorimetric results were followed for $40 \mathrm{~min}$ at $37^{\circ} \mathrm{C}$ using a Multiskan photometer (Thermo Fisher Scientific, Waltham, MA, USA). In parallel, a standard curve was

120 established using four $1 / 2$ serial dilutions of a $100-\mathrm{pg} / \mathrm{ml}$ standard solution that was provided

121 in the kit. The mean change in the absorbance over time was calculated and the titres were 122 expressed based on the standard curve. The test was performed in duplicate and the result 123 was the mean of the duplicates. The results were considered to be positive when the result 124 was $\geq 80 \mathrm{pg} / \mathrm{ml}$. Overflow results preventing reliable absolute quantification were assigned a 125 value of $\geq 500 \mathrm{pg} / \mathrm{ml}$. When the results were discordant and associated with a coefficient of 126 variation (CV) of the duplicates above $20 \%$, the test was repeated in duplicate, and the first 127 results were discarded. Of note, high concentrations of hyperbilirubinemia and 128 hypertriglyceridemia are known to cause false negative results. ${ }^{20}$ 
For the WA, $900 \mu \mathrm{l}$ of pre-treatment buffer were added to $100 \mu \mathrm{l}$ of serum, heated at $13170^{\circ} \mathrm{C}$ for $10 \mathrm{~min}$, and cooled on ice. Then, $200 \mu \mathrm{l}$ of this pre-treated sample were added to a 132 vial containing freeze-dried Limulus amoebocyte lysate. The speed of the increase in the 133 turbidity of the sample was then continuously measured over 90 min using a dedicated MT1346500 toxinometer (FUJIFILM Wako Chemicals, Osaka, Japan). The pre-set calibration curve 135 that was provided by the manufacturer for each reagent lot was used for quantification. The positivity threshold was $\geq 11 \mathrm{ng} / \mathrm{ml}$ and the manufacturer does not recommend retesting positive samples. No significant interference with WA were reported as mentioned by the manufacturer.

Statistical analysis

141 The mycological diagnosis was established using microscopy, culture, GM, and diagnostic quantitative PCR results for $\mathrm{PCP},{ }^{21}$ no matter what the $\mathrm{BDG}$ result was that was transmitted to the clinician. Therefore, the BDG performance was calculated without integrating the BDG result, except for the diagnosis of hepato-splenic candidiasis where the BDG result was used as a criterion for establishing the diagnosis (both FA and WA were positive with 275.2 and $11.89 \mathrm{pg} / \mathrm{ml}$, respectively). Diagnostic performances of both FA and WA tests were calculated for patients with invasive aspergillosis, candidiasis (including one case of hepato-splenic candidiasis), fusariosis, and PCP. A receiver operating characteristic (ROC) curve was drawn for each assay, and the area under the curve (AUC) was calculated. The best Youden index indicated the optimal diagnostic threshold. Sensitivity and specificity of both assays were compared using McNemar's chi-square test. To determine the correlation between the BDG titres, we performed linear regression on samples ranging from 31 to $500 \mathrm{pg} / \mathrm{ml}$ for $F A$ and from 2.359 to $600 \mathrm{pg} / \mathrm{ml}$ for WA. All statistical analyses were performed using Prism v9.0 (GraphPad software). $\mathrm{P}<0.05$ was considered to be significant).

\section{Ethics Statement}

157 The study was a non-interventional evaluation of a new test with no change in the usual procedures, and the clinicians were blinded to the evaluated test results. The clinical data were collected and registered with the approval of our hospital review committee (reference number: 2018000000077). French Public Health Law (CSP Art L1121-1.1) does not require specific approval from an ethics committee for this kind of study, which is exempt from the requirement for informed consent. The 2015 STARD guidelines for diagnostic accuracy studies were followed. ${ }^{22}$ 


\section{RESULTS}

167 We prospectively tested 321 serum samples from 171 patients (sex ratio $M / F, 102 / 69$ [1.48]; 168 mean age, $48 \pm 16$ years) who mainly had haematological conditions $(62 \%$; 106/171) using both 169 assays. Four patients were tested during two different hospitalisations that were more than 30 170 days apart (two before and after allogeneic human stem cell transplantation and two during 171 two different chemotherapy courses). Thus, the analyses were performed considering 175 IFD

172 suspicion episodes with a median of one [range, 1-11] sample per episode. There were 25 173 IFD episodes (PCP $n=12$; invasive aspergillosis $n=5$; candidemia $n=3$; invasive fusariosis $n=2$; 174 hepato-splenic candidiasis $n=1$; mucormycosis $n=1$; and cryptococcosis $n=1$ ) (Table 1). The 175 mucormycosis and cryptococcosis cases were BDG-negative with both assays. Because BDG 176 is known for not being produced at detectable levels in serum by Mucorales and Cryptococcus spp., ${ }^{7}$ these two cases were not included to calculate the performance of the BDG tests.

When considering one sample/episode, the AUC of the two ROC curves was similar 179 (AUC, 0.9) for both assays (Figure 1). Thus, the sensitivity, specificity, positive predictive value 180 (PPV), and negative predictive value (NPV), and positive likelihood ratio (PLR), were as follows 181 for all patients when using a cut-off for positivity of $\geq 120 \mathrm{pg} / \mathrm{ml}$ for FA (Youden $=76.6 \%$ ) and $\geq$ $1824 \mathrm{pg} / \mathrm{ml}$ for WA (Youden = 77.3\%): 81.8\% (95\% confidence interval [Cl]: 61.5-92.7), 94.8\% 183 (95\%Cl: 90.1-97.3), 69.2\% (95Cl\%: 50.0-83.5), 97.3 (95\% $\mathrm{Cl}: 93.3-99.0)$, and 15.75 for FA 184 and $81.8 \%$ (95\%Cl: 61.5-92.7), 95.4\% (95\%Cl: 90.9-97.8), 72\% (95\%Cl: 52.4-85.7), 97.3\% 185 (95\% Cl: IC93.4-99.0), and 18 for WA, respectively. The detailed sensitivities and specificities 186 associated with specific IFD and the optimal thresholds found in this study are presented in 187 Table 2. Results between FA and WA are not very different with WA harbouring a better 188 specificity and with IA being associated with the lowest sensitivity (Table 2).

When using the positivity threshold that is recommended by the manufacturers $(\geq 80$ $\mathrm{pg} / \mathrm{ml}$ for FA and $\geq 11 \mathrm{pg} / \mathrm{ml}$ for WA), the specificity of FA slightly decreased to $90.9 \%(95 \% \mathrm{Cl}$ : 85.3-94.5) but the sensitivity was unchanged (Youden $=72.7 \%$, PLR $=9$ ), and the sensitivity of WA was significantly lower at $50 \%(95 \% \mathrm{Cl}$ : 30.7-69.28, $\mathrm{p}=0.007)$ but the specificity was very similar $96.7(95 \% \mathrm{Cl}$ : 92.6-98.6) (Youden $=46.7 \%, \mathrm{PLR}=15.4)$ (Figure 2). Sensitivities and specificities associated with the optimal thresholds found in this study in various IFD are presented in Table 2.

Overall, among the 321 serum samples, 71 (22.12\%) were from patients with a final diagnosis of bacterial infection and 209 (65.1\%) were obtained from patients without evidence of bacterial infection. Among the 71 samples from patients with bacterial infections, 15 samples

200 The difference was not significant anymore if the 4-pg/ml WA threshold was used $(p=0.11)$.

201 Among these 15 FA-positive samples, seven (47\%) were also WA-positive (of whom four were $202 \geq 11 \mathrm{pg} / \mathrm{ml}$ ). Among the 209 samples from patients with no evidence of bacterial infection, ten 
$203(4.8 \%$ ) had a FA of $\geq 80 \mathrm{pg} / \mathrm{ml}$ (of whom seven were $\geq 120 \mathrm{pg} / \mathrm{ml}$ ) and only one $(0.5 \%$ ) was WA204 positive $>11 \mathrm{pg} / \mathrm{ml}\left(\mathrm{p}<10^{-2}\right)$. This WA-positive sample was not FA-positive $(76 \mathrm{pg} / \mathrm{ml})$, and the result was $<3.7 \mathrm{pg} / \mathrm{ml}$ after retesting.

Multiple serum samples (209 samples; median/episode, 2; range, 2-11) were obtained for 63 episodes, mainly (88.9\%) from haematology patients. Fifty episodes (168 samples) were FA and WA-negative, corresponding to no IFD episodes except for one case of mucormycosis in a haematology patient and one case of cryptococcosis in an AIDS patient. The remaining 41 samples corresponded to samples that were drawn to confirm a first positive result or to follow-up on the effectiveness of the treatment. However, the numbers were too low and the sampling over time was too irregular to allow for a useful comment.

\section{Coefficient of correlation}

215 The correlation coefficient was calculated based on the 30 specimens with $7.8<\mathrm{FA}<500$ and

216 WA $>2.359 \mathrm{pg} / \mathrm{ml}$, which prevented the inclusion of specimens with a quantification that was 217 outside the linearity of both tests. The $r^{2}$ calculated from the correlation between FA and WA was 0.357 , and it was significantly different from zero $\left(\mathrm{p}<10^{-3}\right)$ (Figure 3$)$.

\section{Retesting}

221 According to the FA manufacturer's recommendations, we retested 38/321 (11.8\%) samples 222 that showed discrepant duplicate results (CV >20\%) with 33 of these turning negative (both duplicates $<80 \mathrm{pg} / \mathrm{ml}$ ) and five remaining positive (> $80 \mathrm{pg} / \mathrm{ml}$ ). Arbitrarily, the values that were retained to calculate the performance were the retested values.

Although the WA manufacturer does not recommend retesting, we checked the 34 WA samples that were $\geq 4 \mathrm{pg} / \mathrm{ml}$. The samples were stored at $-20^{\circ} \mathrm{C}$ and the second test was performed after thawing and with a different WA batch. Among the 16 samples that were between $\geq 4$ and $<11 \mathrm{pg} / \mathrm{ml}$ on the first test run, two (12.5\%) became $\geq 11 \mathrm{pg} / \mathrm{ml}$ (one bacterial infection, one PCP) and two (12.5\%) became $<4 \mathrm{pg} / \mathrm{ml}$ (one bacterial infection, one PCP),

230 whereas 12 samples (75\%) remained in the same range. Among the 16 samples that were $231 \geq 11 \mathrm{pg} / \mathrm{ml}$ on the first test, two (12.5\%) became $<4 \mathrm{pg} / \mathrm{ml}$ (one bacterial infection and one with 232 no infection), one (6.25\%) became between $\geq 4$ and $<11 \mathrm{pg} / \mathrm{ml}$ (tested at 12.2, retested at 9.4; one bacterial infection), and $13(81.25 \%)$ remained $\geq 11 \mathrm{pg} / \mathrm{ml}$.

\section{DISCUSSION}

236 Our study is the first prospective study that compared the turbidimetric detection of BDG using 237 WA and colorimetric detection using FA for samples that were routinely sent by clinicians for 238 BDG testing without focusing on a specific IFD or a specific population at risk for IFD. Such 239 analysis had been previously done in retrospective studies that were performed on serum 
240 samples from selected patients with a previous diagnosis of IFD. ${ }^{15-18}$ The present AUCs 241 showed overall similar results for the two assays, as already reported. ${ }^{14,15,17}$ When considering 242 the clinical episodes, the diagnostic performance was highly dependent on the threshold of 243 positivity. Using the manufacturers' thresholds ( $\geq 80 \mathrm{pg} / \mathrm{ml}$ for $\mathrm{FA} ; \geq 11 \mathrm{pg} / \mathrm{ml}$ for WA), FA was 244 more sensitive than WA (81.8\% vs. $50 \%$; $p=0.0002)$ but less specific $(90.9 \%$ vs. $96.7 \%$, $245 \mathrm{p}=0.0002)$, as was already reported. ${ }^{14,15,17}$ When using optimised thresholds according to the 246 ROC curves ( $\geq 120 \mathrm{pg} / \mathrm{ml}$ for $F A$ and $\geq 4 \mathrm{pg} / \mathrm{ml}$ for WA), the sensitivity of both assays was similar 247 (sensitivity $81.8 \%$ vs. $81.8 \%$; specificity $94.8 \%$ vs. $95.4 \%$, p $>0.05$, for FA and WA, 248 respectively).

249 The issue of thresholds is well known to be the key to evaluating serological assays. 250 Mercier et al. performed a retrospective study on 116 PCP cases (both HIV-infected and HIV251 non-infected patients) and 114 controls. ${ }^{15}$ Due to the retrospective design of their study, 252 calculating the predictive values involved simulating the PCP prevalence. When choosing a 253 prevalence of $20 \%$ for PCP to test broncho-alveolar lavage fluids, which is close to what is 254 observed in our hospitals, ${ }^{21}$ the WA NPV was better with their modified cut-off value of 3.616 $255 \mathrm{pg} / \mathrm{ml}^{15}{ }^{15} \mathrm{In}$ another retrospective study that included 120 candidemia and 200 bacteraemia 256 samples as a control group, the optimal cut-off value was $\geq 3.8 \mathrm{pg} / \mathrm{ml}$ for WA. ${ }^{16}$ Very recently, 257 Zubkowicz et al. proposed a threshold at $4.1 \mathrm{pg} / \mathrm{ml} .^{18}$ These optimised cut-offs are close to our 258 threshold of $4 \mathrm{pg} / \mathrm{ml}$ that was observed after our AUC analysis. However, this threshold is lower 259 than the $7 \mathrm{pg} / \mathrm{ml}$ cut-off that was proposed by some authors based on a retrospective analysis 260 of selected IFD patients. ${ }^{17}$ In our study, a cut-off at $7 \mathrm{pg} / \mathrm{ml}$ gives a sensitivity of $72.3 \%$ and a 261 specificity of $96.1 \%$ with a positive likelihood ratio at 18.7 (see supplemental Table 2). Some of this difference between the proposed optimal threshold could be due to the selection of patients with a well-defined IFD, ${ }^{17}$ whereas patients were enrolled prospectively during a period studied by Friedrich et al. ${ }^{16}$ and in the present study. Selecting patients with a welldefined diagnosis avoids borderline patients in whom high titres could be less frequent. However, the low specificity of a test can be overlooked if the goal is to exclude the diagnosis and rely on the NPV, which was excellent in the present evaluation ( $97.3 \%$ for both FA and 268 WA).

On the other hand, a better specificity can avoid useless antifungal treatments that have potential side effects and microbiological pressure leading to acquired resistance of the 271 fungi. In samples from patients with bacterial infection, we observed a $21.1 \%$ and $5.6 \%$ false272 positivity rate for FA and WA, respectively, which is slightly higher than the $15 \%$ and $2 \%$ false273 positivity rate that was observed by Friedrich et al., mainly in the bacteraemia group. ${ }^{16}$ 274 However, it is always difficult to ascertain that the patients with false-positive BDG results had 275 no IFD at all in the absence of a standardised work-up to look for IFD. False WA and FA 276 positivity was mainly observed simultaneously in the same serum samples, which suggests a 
common source of false positivity that is probably due to bacterial antigens. ${ }^{15}$ However, among patients with no bacterial infection, 4.8\% were FA-positive but WA-negative in our study, which suggests than some causes that are responsible for false FA positivity are not encountered with WA, and possibly vice versa.

In our prospective study, BDG testing was not systematic but requested upon suspicion. This potentially result in an increased pre-test probability which can result in an artificial increased performance. Indeed, if a biomarker is tested in a population in which the prevalence of the disease is lower that $5 \%$, the performance of the test will statistically decrease. ${ }^{23}$ The number of IFD analysed in our study is quite small, 25 out of $175(14.2 \%)$ suspicions of IFD episode, which is a limit regarding the performance obtained from both tests. However, as a prospective study on a limited time in an era where clear indication of testing exists, $14 \%$ of IFD episodes in at risk patients is already a high rate of IFD. ${ }^{24}$

The FA positivity threshold could also be discussed. A positive threshold at $120 \mathrm{pg} / \mathrm{ml}$ improves the specificity of the test without much impact on the sensitivity (94.81 vs. 90.9, $p>0.05)$. Other authors have already proposed higher FA thresholds for the diagnosis of invasive candidiasis such as $146 \mathrm{pg} / \mathrm{ml},{ }^{25} 105 \mathrm{pg} / \mathrm{ml},{ }^{17}$ or $350 \mathrm{pg} / \mathrm{ml} .{ }^{26}$ For PCP, relying on a single positivity threshold no matter which patient population is being tested can be misleading, and this is particularly observed in HIV-negative haematological patients. ${ }^{27}$ However, it is difficult to propose different cut-offs according to the IFD before knowing the diagnosis.

If the area under the ROC curves was similar in the present study between FA and WA, we obtained a poor coefficient of correlation $\left(r^{2}=0.357\right)$, which was lower than the previously reported results. ${ }^{14-17}$ However, to obtain the coefficients of correlation, the other authors diluted the samples with FA values $>500 \mathrm{mg} / \mathrm{ml}$, and retested them. We did not perform the tests in a similar manner, and we excluded the overflow values. Another possible reason for the low coefficient of correlation is the high CV of FA, which can impact the comparison. We retested $11.8 \%$ of the serum because of a FA CV of $>20 \%$, which indicated discordant qualitative results between the two duplicates. This figure is much higher than the $3 \%$ of sample retesting that occurs for PCP diagnosis, ${ }^{15}$ but it is similar to the $10 \%$ to $15 \%$ of the samples that were retested for a candidaemia diagnosis. ${ }^{16}$ Although it is not recommended by the WA manufacturer, we retested every sample with a WA result $>4 \mathrm{pg} / \mathrm{ml}$, and we observed some discrepancies, which were mainly in patients without IFD. The causes of these discrepancies should be investigated, knowing that freeze-thaw cycles do not impact BDG values, at least using FA. ${ }^{28}$ When we removed for the coefficient of correlation calculation the two WA-positive (>11 pg/ml) samples which turned negative $(<4 \mathrm{pg} / \mathrm{ml})$ after retesting, the coefficient of correlation considerably 311 improved ( $r^{2}$ from 0.357 to 0.865 ), which strongly suggests that these results were true WA312 specific false-positives. The issue of retesting should then be resolved because of cost issues 313 and to improve the speed of the reporting to the clinicians. Another possibility to limit false- 
314 positive results is to test at least two sequential serum samples. When focusing on patients 315 with haematology malignancies, which is the group with the highest prevalence of IFD, a meta316 analysis showed that two positive consecutive tests had better performance (sensitivity and specificity between $34.0 \%-65.3 \%$ and $97.4 \%-99.5 \%$, respectively) than one positive test. ${ }^{29}$

318 Based on the implementation of routine laboratory testing, there are large differences between the two assays. FA has to be performed on a large series to decrease the cost; the larger the series, the less expensive are the tests. This could delay reporting to a clinician if there is a wait until there are enough samples to fill the ELISA plate. FA is also performed using a low volume ( $5 \mu$ l versus $100 \mu \mathrm{l}$ for WA), which is associated with pipetting error when different technicians perform the test in a routine laboratory. In contrast, WA is a single test that is better adapted for testing on demand, especially for a rapid PCP diagnosis. A new FA format allowing testing Fungitell STAT Assay (Associates of Cape Code Inc.) of one patient at a time is now commercially available and FDA approved to better adapt to clinicians' requirements. ${ }^{30}$

Although this is the first prospective study, we acknowledge some limitations due to a non-formalised format without regular and similar sampling between patients. Therefore, the false-positive results should be interpreted with caution knowing that the extensive work-up for diagnosing IFD was not homogenous between the patients, that bacterial and fungal diseases are often concomitant, ${ }^{20}$ and that such patients receive numerous drugs, which could be a source of false positivity. ${ }^{31,32}$ For the same reasons, we cannot comment on the follow-up evaluation of the antifungal efficacy. ${ }^{33}$ The frequent overflow FA values are less convenient for the follow-up evaluation, unless a new test is performed after dilution, whereas the WA directly provides a wide range of values easy to follow. We could not assess whether performing a second test on sequential samples would result in a better performance of the assays either. ${ }^{25,34}$ However, when no IFDs were reported at the end of the hospitalisation, both assay results remained negative for several samples over time in the present study, which suggests a high NPV.

In conclusion, both assays performed similarly but only when an optimised WA cut-off was used, which was at $4 \mathrm{pg} / \mathrm{ml}$. Thus, we believe that the WA is a single-sample assay that is clinically relevant when a prompt therapeutic decision is required.

\section{Acknowledgements}

346 We acknowledge all the clinicians who cared for the patients with suspected fungal disease.

Conflict of Interest

349 The author declare that Dr Kruger (Fujifilm) provided the Wako tests at no charge for this 


\section{References}

353 1. Colombo AL, de Almeida Júnior JN, Slavin MA, Chen SC-A, Sorrell TC. Candida and invasive mould diseases in non-neutropenic critically ill patients and patients with haematological cancer. Lancet Infect Dis 2017; 17: e344-56.

2. Lortholary $\mathrm{O}$, Renaudat $\mathrm{C}$, Sitbon $\mathrm{K}$, et al. Worrisome trends in incidence and mortality of candidemia in intensive care units (Paris area, 2002-2010). Intensive Care Med 2014; 40: 1303-12.

3. Morrell M, Fraser VJ, Kollef MH. Delaying the empiric treatment of candida bloodstream infection until positive blood culture results are obtained: a potential risk factor for hospital mortality. Antimicrob Agents Chemother 2005; 49: 3640-5.

4. Marchetti O, Lamoth F, Mikulska M, et al. ECIL recommendations for the use of biological markers for the diagnosis of invasive fungal diseases in leukemic patients and hematopoietic SCT recipients. Bone Marrow Transplant 2012; 47: 846-54.

5. Clancy CJ, Nguyen MH. Diagnosing Invasive Candidiasis. J Clin Microbiol 2018: JCM.01909-17.

6. Donnelly JP, Chen SC, Kauffman CA, et al. Revision and Update of the Consensus Definitions of Invasive Fungal Disease From the European Organization for Research and Treatment of Cancer and the Mycoses Study Group Education and Research Consortium. Clin Infect Dis 2019; 46: 1813.

7. Onishi A, Sugiyama D, Kogata $Y$, et al. Diagnostic accuracy of serum 1,3- $\beta$-D-glucan for pneumocystis jiroveci pneumonia, invasive candidiasis, and invasive aspergillosis: systematic review and meta-analysis. J Clin Microbiol 2012; 50: 7-15.

8. Rhein J, Bahr NC, Morawski BM, et al. Detection of High Cerebrospinal Fluid Levels of $(1 \rightarrow 3)-\beta-d-G l u c a n$ in Cryptococcal Meningitis. Open Forum Infect Dis 2014; 1: ofu105.

9. Karageorgopoulos DE, Qu J-M, Korbila IP, Zhu Y-G, Vasileiou VA, Falagas ME. Accuracy of $\beta$-D-glucan for the diagnosis of Pneumocystis jirovecii pneumonia: a meta-analysis. Clin Microbiol Infect 2013; 19: 39-49.

10. Alanio A, Hauser PM, Lagrou K, et al. ECIL guidelines for the diagnosis of Pneumocystis jirovecii pneumonia in patients with haematological malignancies and stem cell transplant recipients. J Antimicrob Chemother 2016; 71: 2386-96.

11. Guigue N, Lardeux S, Alanio A, Hamane S, Tabouret M, Bretagne S. Importance of operational factors in the reproducibility of Aspergillus galactomannan enzyme immune assay. PLoS ONE 2015; 10: e0124044.

12. White PL, Price JS, Posso RB, Barnes RA. An evaluation of the performance of the Dynamiker $\AA$ Fungus (1-3)- $\beta$-D-Glucan Assay to assist in the diagnosis of invasive aspergillosis, invasive candidiasis and Pneumocystis pneumonia. Med Mycol 2017; 55: 84350.

13. Finkelman MA. Specificity Influences in $(1 \rightarrow 3)-\beta-d-$-Glucan-Supported Diagnosis of Invasive Fungal Disease. J Fungi (Basel) 2020; 7: 14. kits available in Japan. $J$ Infect Chemother 2011; 17: 473-7. 

for Diagnosing Pneumocystis Pneumonia: a Direct Comparison between the Wako $\beta$-Glucan Assay and the Fungitell Assay. Warnock DW, ed. J Clin Microbiol 2019; 57: 52.

16. Friedrich R, Rappold E, Bogdan C, Held J. Comparative Analysis of the Wako $\beta$-Glucan

Test and the Fungitell Assay for Diagnosis of Candidemia and Pneumocystis jirovecii

Pneumonia. Diekema DJ, ed. J Clin Microbiol 2018; 56: w14281.

17. De Carolis E, Marchionni F, Torelli R, et al. Comparative performance evaluation of Wako $\beta$-glucan test and Fungitell assay for the diagnosis of invasive fungal diseases. Chalmers J, ed. PLoS ONE 2020; 15: e0236095.

18. Zubkowicz M, Held J, Baier M, et al. Clinical evaluation of two different (1,3)-ß-d-glucan assays for diagnosis of invasive fungal diseases: A retrospective cohort study. Mycoses 2021; 64: 212-9.

20. Pickering JW, Sant HW, Bowles CAP, Roberts WL, Woods GL. Evaluation of a (1->3)beta-D-glucan assay for diagnosis of invasive fungal infections. J Clin Microbiol 2005; 43: 5957-62.

21. Alanio A, Desoubeaux G, Sarfati C, et al. Real-time PCR assay-based strategy for differentiation between active Pneumocystis jirovecii pneumonia and colonization in immunocompromised patients. Clin Microbiol Infect 2011; 17: 1531-7.

22. Bossuyt PM, Reitsma JB, Bruns DE, et al. STARD 2015: an updated list of essential items for reporting diagnostic accuracy studies. BMJ 2015; 351: h5527.

23. Pfeiffer CD, Fine JP, Safdar N. Diagnosis of invasive aspergillosis using a galactomannan assay: a meta-analysis. Clin Infect Dis 2006; 42: 1417-27.

24. Maertens $\mathrm{J}$, Marchetti $\mathrm{O}$, Herbrecht $\mathrm{R}$, et al. European guidelines for antifungal management in leukemia and hematopoietic stem cell transplant recipients: summary of the ECIL 3--2009 update. Bone Marrow Transplant 2011; 46: 709-18. beta-D-glucan to diagnosis of invasive candidiasis after liver transplantation. Warnock DW, ed. J Clin Microbiol 2015; 53: 771-6.

26. Poissy J, Sendid B, Damiens S, et al. Presence of Candida cell wall derived polysaccharides in the sera of intensive care unit patients: relation with candidaemia and Candida colonisation. Crit Care 2014; 18: R135-11.

27. Mercier T, Aissaoui N, Gits-Muselli M, et al. Variable Correlation between Bronchoalveolar Lavage Fluid Fungal Load and Serum-(1,3)- $\beta$-d-Glucan in Patients with Pneumocystosis-A Multicenter ECMM Excellence Center Study. J Fungi (Basel) 2020; 6: 327. (1-->3) beta-D-glucan assay as an aid to diagnosis of fungal infections in humans. Clin Infect Dis 2005; 41: 654-9. 
436 and meta-analysis of cohort studies from the Third European Conference on Infections in 437 Leukemia (ECIL-3). Clin Infect Dis 2012; 54: 633-43.

438 30. D'Ordine RL, Garcia KA, Roy J, Zhang Y, Markley B, Finkelman MA. Performance 439 characteristics of Fungitell STAT ${ }^{\mathrm{TM}}$, a rapid $(1 \rightarrow 3)-\beta$-D-glucan single patient sample in vitro 440 diagnostic assay. Med Mycol 2020; 73: i14.

441 31. Liss B, Cornely OA, Hoffmann D, Dimitriou V, Wisplinghoff H. 1,3- $\beta$-D-Glucan

442 contamination of common antimicrobials. J Antimicrob Chemother 2016; 71: 913-5.

443 32. Marty FM, Lowry CM, Lempitski SJ, Kubiak DW, Finkelman MA, Baden LR. Reactivity of 444 (1-->3)-beta-d-glucan assay with commonly used intravenous antimicrobials. Antimicrob 445 Agents Chemother 2006; 50: 3450-3.

446 33. Guitard J, Isnard F, Tabone M-D, et al. Usefulness of B-D-glucan for diagnosis and 447 follow-up of invasive candidiasis in onco-haematological patients. J Infect 2018; 76: 483-8.

448 34. Odabasi Z, Mattiuzzi G, Estey E, et al. Beta-D-glucan as a diagnostic adjunct for invasive 449 fungal infections: validation, cutoff development, and performance in patients with acute 450 myelogenous leukemia and myelodysplastic syndrome. Clin Infect Dis 2004; 39: 199-205. 
Table 1: Repartition of the 175 episodes of suspected invasive fungal diseases (IFD) according to the underlying diseases/conditions and according to the final diagnosis of IFD, bacterial sepsis, or no IFD.

\begin{tabular}{|c|c|c|c|c|c|c|}
\hline $\begin{array}{l}\text { Underlying } \\
\text { disease/condition }\end{array}$ & $\begin{array}{c}\text { Invasive } \\
\text { aspergillosis } \\
n=5\end{array}$ & $\begin{array}{l}\text { Candidaemia } \\
\qquad n=3\end{array}$ & $\begin{array}{l}\text { Pneumocystosis } \\
n=12\end{array}$ & $\begin{array}{l}\text { Other IFD a } \\
\qquad n=5\end{array}$ & $\begin{array}{c}\text { Bacterial } \\
\text { sepsis } \\
n=39\end{array}$ & $\begin{array}{l}\text { No IFD } \\
n=111\end{array}$ \\
\hline $\begin{array}{l}\text { Haematological } \\
\text { malignancies } n=120\end{array}$ & 3 & 3 & 3 & 2 & 29 & 80 \\
\hline Solid cancer $\mathrm{n}=12$ & 0 & 0 & 2 & 0 & 2 & 8 \\
\hline $\begin{array}{l}\text { Solid organ } \\
\text { transplantation }^{b} n=10\end{array}$ & 1 & 0 & 0 & 0 & 1 & 8 \\
\hline $\begin{array}{l}\text { Inflammatory disease } \\
n=6\end{array}$ & 0 & 0 & 3 & 0 & 0 & 3 \\
\hline AIDS $n=13$ & 0 & 0 & 4 & 1 & 1 & 7 \\
\hline $\mathrm{ICU}^{\mathrm{c}} \mathrm{n}=7$ & 0 & 0 & 0 & 0 & 5 & 2 \\
\hline Diabetes $n=2$ & 1 & 0 & 0 & 1 & 0 & 0 \\
\hline Others $^{d} n=5$ & 0 & 0 & 0 & 1 & 1 & 3 \\
\hline
\end{tabular}

a invasive fusariosis $n=2$; hepato-splenic candidiasis $n=1$; mucormycosis $n=1$; $\operatorname{cryptococcosis} n=1$

${ }^{b}$ kidney $n=7$; kidney pancreas $n=2$; liver $n=1$.

${ }^{\mathrm{c}}$ out of which 6 with acute respiratory distress syndrome

d unspecified pneumonia $n=3$; sepsis $n=1$; mycetoma $n=1$ 
Table 2: Sensitivity and specificity of FA and WA with definite thresholds in various IFD.

\begin{tabular}{lllllll}
\hline \multirow{2}{*}{ Type of IFI } & $\begin{array}{l}\text { Test and threshold } \\
\text { used }\end{array}$ & $\begin{array}{l}\text { Sensitivity } \\
(\%)\end{array}$ & IC 95 & $\begin{array}{l}\text { Specificity } \\
\text { (\%) }\end{array}$ & IC 95 & Likelihood ratio \\
\hline Invasive aspergillosis & FA $(120 \mathrm{pg} / \mathrm{ml})$ & 57.14 & $18.41 \%$ to $90.10 \%$ & 91.52 & $87.64 \%$ to $94.49 \%$ & 6.738 \\
& WA $(4 \mathrm{pg} / \mathrm{ml})$ & 57.14 & $18.41 \%$ to $90.10 \%$ & 96.82 & $94.05 \%$ to $98.54 \%$ & 17.97 \\
PCP & FA $(120 \mathrm{pg} / \mathrm{ml})$ & 78.57 & $49.20 \%$ to $95.34 \%$ & 91.52 & $87.64 \%$ to $94.49 \%$ & 9.265 \\
& WA $(4 \mathrm{pg} / \mathrm{ml})$ & 71.43 & $41.90 \%$ to $91.61 \%$ & 96.82 & $94.05 \%$ to $98.54 \%$ & 22.46 \\
Candidiasis & FA $(120 \mathrm{pg} / \mathrm{ml})$ & 72.73 & $39.03 \%$ to $93.98 \%$ & 91.52 & $87.64 \%$ to $94.49 \%$ & 8.576 \\
& WA $(4 \mathrm{pg} / \mathrm{ml})$ & 72.73 & $39.03 \%$ to $93.98 \%$ & 96.82 & $94.05 \%$ to $98.54 \%$ & 22.87 \\
All IFI & FA $(120 \mathrm{pg} / \mathrm{ml})$ & 81.82 & $61.48 \%$ to $92.69 \%$ & 94.81 & $90.08 \%$ to $97.34 \%$ & 15.75 \\
& WA $(4 \mathrm{pg} / \mathrm{ml})$ & 81.82 & $61.48 \%$ to $92.69 \%$ & 95.45 & $90.92 \%$ to $97.78 \%$ & 18 \\
\hline
\end{tabular}




\section{Figure legends}

467 Figure 1. Receiver operating characteristic (ROC) curves and area under the curve (AUC) of 468 the Fungitell assay (FA, dashed blue line) and the Wako assay (WA, green line). The optimised 469 thresholds for positivity in FA assay (120 pg/ml in blue) and in WA (4 pg/ml in green) are 470 marked with an arrow. The manufacturers' thresholds are mentioned in black $(80 \mathrm{pg} / \mathrm{ml}$ for FA 471 and $11 \mathrm{pg} / \mathrm{ml}$ for WA).

472

473 Figure 2. Violin plots of the beta-D-glucan (BDG) levels that were measured using the Fungitell 474 assay (FA, A and C) and the Wako assay (WA, B and D) for the 175 episodes of suspected 475 invasive fungal diseases (IFD). The dashed lines represent the manufacturers' thresholds (80 $476 \mathrm{pg} / \mathrm{ml}$ for FA and $11 \mathrm{pg} / \mathrm{ml}$ for WA) and the dotted line represents the optimised threshold (120 $477 \mathrm{pg} / \mathrm{ml}$ for FA and $4 \mathrm{pg} / \mathrm{ml}$ for WA) according to the receiver operating characteristic curves from 478 the present study.

479 IFD, invasive fungal diseases; IA, invasive aspergillosis; IC, invasive candidiasis; PCP, 480 pneumocystosis.

481

482 Figure 3. Linear regression of results for the BDG concentrations that were determined using 483 the Fungitell (FA) and Wako (WA) assays based on 28 specimens within the reliable range $484(7.8<F A<500 \mathrm{pg} / \mathrm{ml}$ and $\mathrm{WA}>2.359 \mathrm{pg} / \mathrm{ml}) . \mathrm{r}^{2}=0.354, \mathrm{p}<0.001$. The dashed lines represent 485 the $95 \%$ confidence interval. 